\title{
NANOCRYSTALLIZATION IN IRON ALLOYS \\ INDUCED BY FRICTION TREATMENT AND NITROGEN DIFFUSION
}

\author{
A. Yurkova ${ }^{a}$, F. Belots 'ky ${ }^{a}$, A. Byakova ${ }^{a, b}, Y^{a}$. Podrezov ${ }^{b}$, M. Danylenko ${ }^{b}$ \\ ${ }^{a}$ National Technical Universsity of Ukraine "Kiev Polytechnic Institute", Kiev, Ukraine \\ ${ }^{b}$ Frantcevych Institute for Problems of Materials Science, Kiev, Ukraine
}

\begin{abstract}
It was found that both surface friction treatment in inert gas (FT) and friction nitriding in ammonia atmosphere (FN) are capable to form gradient nanostructured surface layers on Fe-alloys. Specific features of the nanostructured surface layers were investigated using XRD-analysis, optical and transmission electron microscopy (TEM).
\end{abstract}

Key words: nanostructured materials, iron-alloys, friction treatment, nitriding

\section{INTRODUCTION}

The combination of the processes of the severe plastic deformation of the surface with their physical-chemical treatment can provide the unique opportunity of the controlled formation of nano-sized grain structure for the strength and corrosion stability increasing. By applying both surface plastic deformation and nitriding process simultaneously nanostructured material could be determined. This kind of surface treatment related to refinement of grain could be helpful for considerable modification of material service properties.

The use of severe high rate friction treatment can give grain structure of different scale, i.e. nano-, submicro-, and micro-sized grain structures. These structures of different grain scale take place one after another in the direction to center of sample when deformed surface layer has been formed. 
Objective of this work is to investigate the specific features of modified layer structure formed on the surface of $\mathrm{Fe}$ alloys by friction treatment being occurred in nitrogen medium.

\section{EXPERIMENTAL}

The samples from Armco $\mathrm{Fe}$ and $\mathrm{Fe}-\mathrm{Ti}(0.7 ; 1.2 ; 1.6 \mathrm{wt} . \% \mathrm{Ti})$ alloys were treated by friction for obtaining the surface layer of nanocrystalline structure. Before treatment the samples were annealed in vacuum at the temperature as high as $1373 \mathrm{~K}$ to obtain homogeneous coarse grain structure and also to refuse the effect of previous mechanical treatment. Duration of annealing process was about to $360 \mathrm{~min}$. The average grain size of annealed samples was $100-150 \mu \mathrm{m}$.

According to procedure published previously the cylindrical samples were heated by friction during sample rotation [1]. Hard alloy blocks being pressed to sample surface were used for friction process. Friction treatment was held either in Ar-gas (FT) or in ammonia medium (FN). The temperature of sample ranged from 773 to $853 \mathrm{~K}$ was controlled by chromelalumel thermocouple. Duration of treatment was about to $60 \mathrm{~min}$. After FT and FN processes the sample surface was smooth similar to that of original polished one.

$\mathrm{X}$-Ray diffraction analysis of the surface layer was performed by X-ray diffractometer $(20 \mathrm{kV})$ with $\mathrm{Fe} K_{\alpha}$ radiation. By using repeated electrochemical etching the treated surface layers were removed layer-bylayer. Thus, the grain structure in the direction from the treated surface to sample center was investigated using stepwise XRD analysis. The average grain size was determined by Scherrer method using the broadening of bcc Fe Bragg diffraction peaks compared to annealed sample [2].

The structure of modified surface layer was investigated using powerful optical microscope Neophot-21 (resolution up to $0.4 \mu \mathrm{m}$ ). Furthermore, TEM images and selected area electron diffraction (SAED) patterns were obtained to study structural evolution caused by simultaneous friction treatment and nitriding.

\subsection{RESULTS}

Table 1 shows structural parameters and Vickers hardness of modified layers formed by simultaneous friction treatment and nitriding. 
Table 1. Surface layers parameters after friction treatment

\begin{tabular}{|c|c|c|c|c|c|c|}
\hline $\begin{array}{c}\text { Sample } \\
\text { material }\end{array}$ & $\begin{array}{c}\text { Treat- } \\
\text { ment } \\
\text { type }\end{array}$ & $\begin{array}{c}\text { Layer } \\
\text { depth, } \\
\mathrm{mm}\end{array}$ & $\begin{array}{c}\mathrm{HV}, \\
\mathrm{GPa}\end{array}$ & $\begin{array}{c}\text { Phase } \\
\text { composit } \\
\text { ion }\end{array}$ & $\begin{array}{c}\alpha \text {-phase } \\
\text { 1attice para- } \\
\text { meter, nm }\end{array}$ & $\begin{array}{c}\text { Nitrogen } \\
\text { content in } \\
\alpha \text {-phase, } \\
\text { wt.\% }\end{array}$ \\
\hline \multirow{2}{*}{ Armco Fe } & FT & 0.1 & 4.5 & $\alpha$ & 0.28667 & - \\
\cline { 2 - 7 } & FN & 0.45 & 6.5 & $\alpha_{N}+\gamma^{\prime}$ & 0.2871 & 0.32 \\
\hline Fe+0.7wt.\%Ti & FN & 0.33 & 9 & $\alpha_{N}+\gamma^{\prime}$ & 0.2874 & 0.58 \\
\hline $\mathrm{Fe}+1.1$ wt.\%Ti & FN & 0.22 & 11 & $\alpha_{N}+\gamma^{\prime}$ & 0.2890 & 0.65 \\
\hline Fe+1.2wt.\%Ti & FT & 0.06 & 7 & $\alpha$ & 0.28725 & - \\
\cline { 2 - 7 } & FN & 0.15 & 12 & $\alpha_{N}+\gamma^{\prime}$ & 0.2893 & 0.7 \\
\hline Fe+1.6wt.\%Ti & FT & 0.13 & 13.7 & $\alpha_{N}+\gamma^{\prime}$ & 0.2920 & 0.85 \\
\hline
\end{tabular}

Grain morphology (size and shape) of modified surface layers is different compared to central part of sample, as shown in Fig. 1. Both FT process and FN one cause to refinement of surface layer grain structure. Additionally, increasing the grain boundaries extension occurs. The depth of modified layer determined by FN-process is larger than that formed by FT-process (Tab. 1, Fig 1). Gradient of grain size across cross-section of modified layer occurs due to friction. Gradient of deformation results in grain structure gradient. Fine-grained structure is observed only on short distance to the surface. Fig 1a, b shows that optical microscopy was not helpful to recognize grain size located very close to surface.
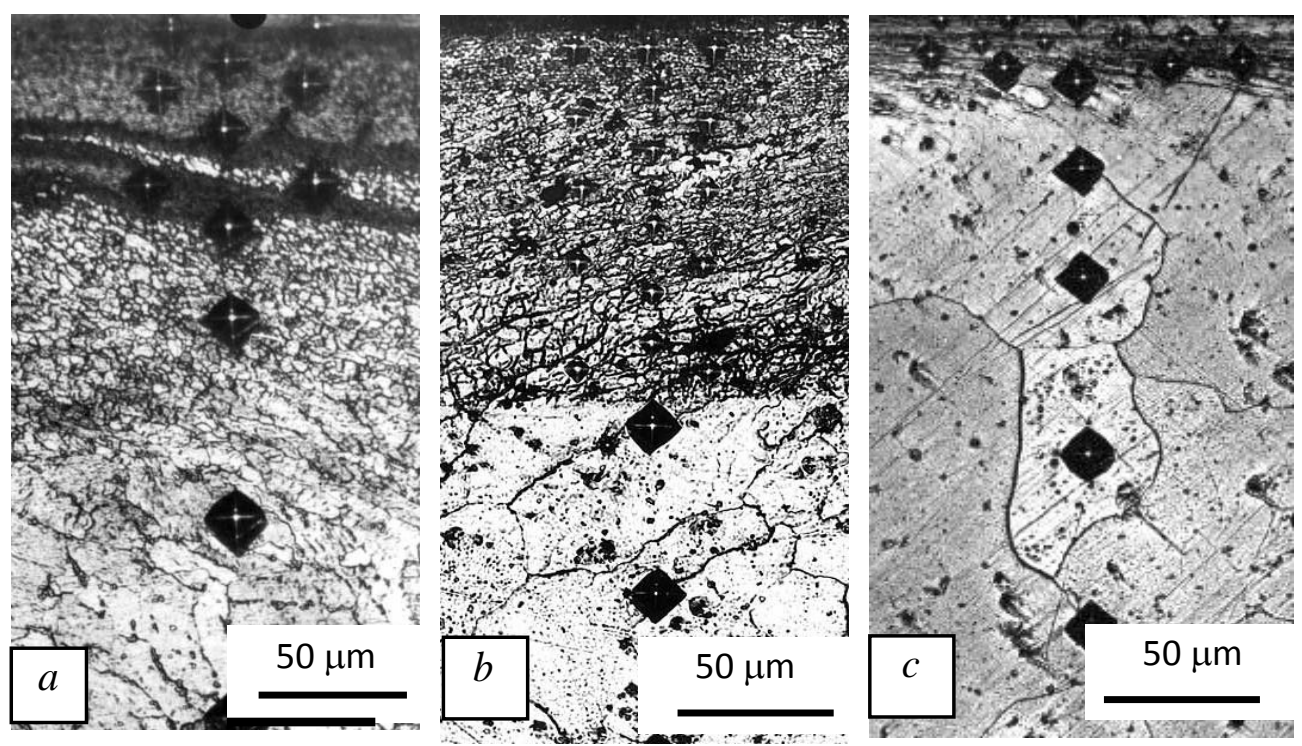

Fig. 1 - Optical micrographs of structure observed in cross-section of treated sample: $a-$ Armco Fe treated by FN process at $773 \mathrm{~K}$ during $60 \mathrm{~min} ; \quad b-\mathrm{Fe}+1.2 \mathrm{wt} . \% \mathrm{Ti}$, treated by FN process at $823 \mathrm{~K}$ during $60 \mathrm{~min} ; c-\mathrm{Fe}+1.2 \mathrm{wt} . \% \mathrm{Ti}$, treated by FT process at $823 \mathrm{~K}$ during $60 \mathrm{~min}$. 
According to the results obtained in the present study (see Tab.1) nitrogen content in $\alpha_{N}$-phase is higher that formed by usual nitriding without friction. For modified layer formed on Armco Fe nitrogen content in $\alpha_{N}$-phase is higher by 3 times than that indicated by state diagram for system Fe-N [3]. It was assumed that the essential increase of nitrogen content in $\alpha_{N}$-phase could be caused both by the increase of dislocation density and by the increase of grain boundaries occurred due to grain refinement. To verify this assumption dislocation density was determined by XRD method analysis when physical broadening the diffraction peaks is used [4]. Dislocation density was calculated using the equation:

$$
\rho=\frac{3 \beta^{2} \operatorname{ctg}^{2} \theta}{K^{\prime} b^{2} l}
$$

where $\rho$ - dislocation density; $\beta$ - XRD diffraction peak broadening; $K^{\prime}-$ coefficient that depends on both reciprocal lattice vector orientation and dislocation type; $b-$ Burgers vector length; $1 \approx 5$ is the constant taken for condition of random dislocation distribution; $\theta$ - Bragg angle.

The annealed sample that was not treated by friction has been used as a standard one. Dislocation density caused by friction process was investigated using the sample treated in Ar-gas medium at $823 \mathrm{~K}$ during $60 \mathrm{~min}$. For the sample treated by friction calculated dislocation density was determined in the range from $10^{10}$ to $10^{11} \mathrm{~cm}^{-2}$ whereas that for the annealed sample was obtained in the range $10^{6}$ to $10^{8} \mathrm{~cm}^{-2}$. Thus, plastic deformation occurred due to friction causes the increase of total dislocation density.

Broadening the diffraction peaks of $\alpha_{N}-$ phase formed in modified layer indicates that substructure that was consisted of small individual blocks could be formed additionally inside the grains being refined by friction. Blocks size of bcc-Fe being formed at the very surface layer of the sample treated by FT process was about to $16 \mathrm{~nm}$. Compared to the above block size of $\alpha_{N}$-phase formed by FN process is found about to $8 \mathrm{~nm}$ while it was not more then $10-15 \mathrm{~nm}$ at the distance to $0.1 \mathrm{~mm}$ from the surface. Indications were obtained that block size increases mostly up to submicro-scaled one when the distance from the surface increases.

Bright-field TEM images of surface for the samples treated either by FT process or by FN one are shown in Fig. 2. Blurred rings related to bcc-Fe treated by FT process can be caused by high degree of grain refinement. Since nanostructured layer determined by FT process was too small, separate spots placed on blurred diffraction rings is observed, as shown in Fig.2a. These spots occur because of submicro-scaled bcc-Fe that is placed beneath nanostructured surface layer. When the samples were treated by FN process, blurred rings, which could be associated both with grain Kefinement of $\alpha_{N}$-phase and with coherent nitrogen precipitations, are recorded only (see Fig.2b, c). 




Fig. 2. Bright-field TEM images showing $(a, b, c)$ microstructures of surface layer and $(d)$ that determined at the distance of $0.1 \mathrm{~mm}$ from the surface: $a, b$-Armco Fe treated by FT and FN processes at $773 \mathrm{~K}$ during 60 min respectively; $c, d-\mathrm{Fe}+0.7 \mathrm{wt} . \% \mathrm{Ti}$ treated by FN process at $823 \mathrm{~K}$ during $60 \mathrm{~min}$. Inserts present SAED pattern

It is seen in Fig. 2 that both FT process and FN one result in formation of nanostructure consisted of polyhedral cells/blocks of different sizes.

Two different groups of cells/blocks could be pointed out and classified considering to their sizes, which were determined directly using TEM images and by means of calculations using electron diffraction patterns [2]. The first group unites the cells/blocks of largest sizes, which are ranged from 150-200 nm and from 50 to $70 \mathrm{~nm}$ for FT and FN processes respectively. The second group includes the cells/blocks, which have the smallest sizes. They are located inside the cells/blocks of the first group. FN process causes the formation cells/blocks of second group for which their sizes were ranged from 5 to $10 \mathrm{~nm}$. The each cell/block is rounded either by dislocation walls or dislocation tangles, forming sub-boundaries.

Fig. $2 \mathrm{~d}$ shows that instead of blurred rings belonged to $\alpha_{\mathrm{N}}$-phase, which were determined in the modified layer formed in the samples treated by FN process, individual blurred spots are detected in SAED pattern when the distance to surface was about to $0.1 \mathrm{~mm}$. Additionally, blurred rings belonged to fcc $\gamma^{\prime}$-phase appears in SAED pattern. Several aspects could be mentioned considering the results obtained by TEM analysis. The first is that the nanostructured $\alpha_{N}$-phase transforms in submicro-scaled one as distance to the surface increases. Additionally, coherence disruption happens and, if so, inclusions of $\gamma^{\prime}$-phase are formed.

It should be note the important role of nitrogen diffusion for determining the nanostructured material. Nitrogen atoms being consolidated at the sub-boundaries could block the processes of recovery and stress relaxation, resulting in pronounces refinement of grain structure. 


\section{CONCLUSION}

It was found that both surface friction treatment in inert gas (FT) and friction nitriding in ammonia atmosphere (FN) are capable to form gradient nanostructured surface layers on Fe-alloys. By using XRD-analysis and TEM technique polyhedral cells/blocks of different sizes are recognized in grains of $\alpha$-phase. Two different groups of cells/blocks were pointed out and classified considering to their sizes. The first group united the cells/blocks of largest sizes whereas the second group included the cells/blocks, which are located inside the cells/blocks of the first group and have the smallest sizes ranged for FN process from 5 to $10 \mathrm{~nm}$. Generally, FN process resulted in the cells/blocks of smaller sizes than that caused by FT process. The sizes of the first group of cells/blocks were ranged from 150-200 nm and from 50 to $70 \mathrm{~nm}$ for FT and FN processes respectively. It was assumed that nitrogen atoms being consolidated at the sub-boundaries could block the processes of recovery and stress relaxation, resulting in pronounces refinement of grain structure.

\section{ACKNOWLEDGEMENTS}

This research was supported by Ministry of Education and Science of Ukraine, project No 2528, and National Academy of Science of Ukraine, theme C-13.

\section{REFERENCES}

1. Bilots `ky A.V., Yurkova A.I.Strengthening of Valve Steel by Friction Nitriding // Technologiya i Organizatziya Proizvodstva -1988, № 2, pp.40-41.

2. Structure of Metals. Cristallographyc Methods, Principles and Data. C.S.Barrett, T.B.Massalski. Pergamon Press. Oxford - New York. 1980.

3. V.G.Paranjipe, M.Cohen, M.B.Bever, and C.F.Floe. J.Metals. 1950, 182, No2, p.261-267.

4. A.N.Ivanov, Yu.O.Megenniy, A.E.Ostrov, and E.I.Fomichova. Zavodskaya Laboratoriya-1987, No2, p.43. 